\title{
RETROSPECTIVE ANALYSIS OF MAXILLOFACIAL TRAUMA IN MAKKAH CITY, SAUDI ARABIA
}

\author{
Asmaa T..Ashour ${ }^{*}$, Samahir A. Bashraheel ${ }^{* *}$, Alaa Z.Makki ${ }^{* * *}$ and Mohamed.Foda ${ }^{* * * *}$
}

\begin{abstract}
Objective: This study was aimed to analyze retrospectively the demographic data, incidence, etiology and different treatment modalities of maxillofacial fractures in patients managed at $\mathrm{Al}$ Noor Hospital-Trauma Center, Makkah City, Saudi Arabia during a 2-year period.

Patients and Methods: A total of 223 patients with maxillofacial trauma referred to and diagnosed at the Maxillofacial Department, Al-Noor hospital, Makkah City between December 2010 and November 2012 were assessed in this retrospective study according to their age, sex, etiology, medical/dental history, chief complaint, site and distribution of facial fractures, in addition to the definitive diagnosis and treatment of the case. Data of each patient were collected on a sheet and then transferred to an SPSS (ver. 16.0; SPSS Inc., Chicago, IL, USA) spreadsheet for statistical analysis. The chi-square test was used to test the association between two categorical variables or factors
\end{abstract}

Results: In these 2-years retrospective study, the reported cases of the maxillofacial trauma were most frequent in males (84.8\%) than females (15.2\%), and the affected decay was 21-30 $(37.2 \%)$. Motor Vehicle crashes were the most common etiology among all assessed cases, except in those with age $<10$ years whereby fall was the most frequent cause. The majority of cases were mandible fractures $(46.6 \%)$, particularly ramus followed by the angle and the body of the mandible. Extremities trauma (16.6\%) and other associated traumas were also reported. Among the 223 referred patients, survival rate was $97.8 \%$, and the most applied treatment was open reduction and internal fixation $(59.3 \%)$ followed by closed reduction and internal fixation (22.0\%).

Conclusion: These findings support the view that the incidence of maxillofacial fractures secondary to motor accidents is common in Saudi Arabia, particularly among males, perhaps as a result of the conservative nature of Saudi society, as the rules of Saudi Arabia do not allow the females to drive during research performing. Therefore, we recommend the high demand for the application of stricter traffic rules and to ensure strict compliance of these traffic regulations to reduce the rate of MVC.

KEY WORDS: maxillofacial trauma, Makkah City, Two-year retrospective study.

\footnotetext{
* Dental center, Al-Noor Specialty Hospital, Makah City, Saudi Arabia

** Medical Center of the King Abdelaziz University , Jeddah , Saudia Arabia

*** Head of the department of the oral and maxillofacial surgery UQUDENT Makah City, Saudi Arabia **** Oral and Maxillofacial Surgery Department, Faculty of Dentistry, Al-Azhar University, Assiut Branch
} 


\section{INTRODUCTION}

Maxillofacial trauma is any trauma to the face that can involve soft tissue injuries or fractures of the facial bones such as nasal bone, the maxilla, the mandible, the zygoma, the frontal bone, the palate, and the orbit (Lee 2012), and it remains one of the common causes of grave concern due to the increasing road traffic accidents, violence and sports injury (Barde et al., 2014).

Maxillofacial trauma can be complex, and can result in both acute and long-term divesting emotional sequelae, psychological problems and functional disturbance (Auerbach et al., 2008; Mansuri et al., 2013). Additionally, maxillofacial trauma also causes considerable economic expense due to procedural costs, the time a patient is off work, and the associated loss of income (Chrcanovic, 2012).

The goal of maxillofacial surgical treatment is full restoration of function and aesthetics. Treatment of lower and upper jaw fractures focuses on reducing the fragments so that dental occlusion is normal. Other midface fracture reductions require additional exact orbital rim alignment. Immobilization of fractures can require various combinations of intermaxillary fixation, interosseous wiring, suspensory wires from intraoral arch bars, transfacial Kirschner wires, occasional maxillary antral packs, and rare external fixation with headframes or external pins (Bowers et al., 1977) .

Anatomically, fractures of the mandible were classified into 8 regions: symphysis, parasymphysis, canine region, body, angle, ramus, coronoid process and condyle. Midface fractures were classified into three groups: bilateral midface fractures, unilateral midface fractures, isolated nasal bone fracture. Bilateral midface fractures were classi- fied according to the Le Fort classification. Unilateral midface fractures were classified into five groups: isolated zygomatic arch fracture, zygomatic fracture, isolated infraorbital rim fracture, fracture of anterior wall of maxillary sinus and others. The unilateral midface fractures were also classified according to their anatomical presentation, i.e. anterior sinus wall, infrazygomatic crest, the fronto-zygomatc suture and the zygomatic arch.

Although there is a worldwide increase in maxillofacial trauma incidence; the epidemiology and etiology of these injuries varies widely across countries throughout the world, and even within the same country depending on several cultural socioeconomic, and environmental factors (Mabrouk et al., 2014).

An understanding of maxillofacial trauma pattern of different countries together with a knowledge of different laws (seat belts for drivers, helmets for motorcyclists, speed limits, and protection worn during sports and at work) is crucial to establish effective measures for injury prevention and treatment (Boffano et al., 2014).Therefore, management of maxillofacial injuries should include not only treatment of the acute phase, but also combine preventive strategies, interventional programs and modifications of the societal attitudes and behaviors to reduce their incidence and the direct and indirect costs of their sequelae (Chrcanovic 2012; Boffano et al., 2014).

In this concept, the patterns of maxillofacial trauma in Saudi Arabia are still poorly studied (Abdullah et al., 2013), particularly in the western region including Makkah City. Thus, the aim of the present study was to examine the etiologies and patterns of maxillofacial fractures among patients referred to Al-Noor

Hospital, Makkah City, Saudi Arabia between 2011 and 2012, and this to help guide the development of new methods of maxillofacial trauma prevention, preventative measures in Saudi Arabia.

\section{PATIENTS AND METHODS}

Ethical approval for this retrospective study was obtained from the local institutional review board at the College of Dentistry Research Center, King Abdul-Aziz University (KAU) and Al-Noor hospi- 
tal in Makkah City, Saudi Arabia. Al-Noor hospital is one of the main hospitals in Makkah City with maxillofacial facilities affiliated with the Ministry of Health of Saudi Arabia.

The data and charts of all outpatients, inpatients, and emergency department patients at the Al-Noor hospital in Makkah City from

December 2010 to November 2012 were analyzed. After excluding patient files with incomplete or unclear records, the files of 223 patients with a diagnosis of maxillofacial trauma were included in the study. The following data were recorded for each patient: sex and age; facial trauma and fracture pattern; cause of injury; and other associated injuries.

Data were recorded on a special data sheet and transferred to an SPSS (ver. 16.0; SPSS Inc., Chicago, IL, USA) spreadsheet for statistical analysis. The chi-square test was used to test the association between two categorical variables or factors.

\section{RESULT}

In the present 2-year period retrospective study, data from the files of 223 patients with diagnosed maxillofacial trauma were analyzed.

\section{Distribution of patients in relation to sex, age, etiology and survivability}

The enrolled patients were of both sexes and aged 1-75 years, and their distribution according to sex, age, etiology, and discharge status was shown in Tables $1 \& 2$.

TABLE (1) Distribution of the enrolled 223 patients based on their sex, age, etiology of maxillofacial traumas and discharge status Parameter

\begin{tabular}{|c|c|c|c|c|}
\hline & & Number & Percentage & Total \\
\hline \multirow[t]{2}{*}{ Sex } & Male & 189 & $84.8 \%$ & \multirow{2}{*}{$\begin{array}{l}F=223 \\
P=100 \%\end{array}$} \\
\hline & Female & 34 & $15.2 \%$ & \\
\hline \multirow[t]{7}{*}{ Age (Year) } & $0-10$ & 24 & $10.8 \%$ & \multirow{7}{*}{$\begin{array}{l}F=223 \\
P=100 \%\end{array}$} \\
\hline & $11-20$ & 54 & $24.2 \%$ & \\
\hline & 21- 30 & 83 & $37.2 \%$ & \\
\hline & $31-40$ & 28 & $12.6 \%$ & \\
\hline & $41-50$ & 19 & $8.5 \%$ & \\
\hline & $51-60$ & 8 & $3.6 \%$ & \\
\hline & $60-75$ & 7 & $3.1 \%$ & \\
\hline \multirow[t]{5}{*}{ Etiology } & Motor vehicle crashes (MVC) & 145 & $65 \%$ & \multirow{5}{*}{$\begin{array}{l}F=223 \\
P=100 \%\end{array}$} \\
\hline & Falls & 43 & $19.3 \%$ & \\
\hline & Violent Assaults & 21 & $9.4 \%$ & \\
\hline & Sports & 7 & $7 / 223$ & \\
\hline & Others & 7 & $7 / 223$ & \\
\hline \multirow[t]{2}{*}{ Discharge Status } & Alive & 218 & $\mathbf{9 7 . 8 \%}$ & \multirow{2}{*}{$\begin{array}{l}\mathrm{F}=223 \\
\mathrm{P}=100 \%\end{array}$} \\
\hline & Death & 5 & $2.2 \%$ & \\
\hline
\end{tabular}


TABLE (2) Causes of maxillofacial trauma in relation to sex and age of analyzed 223 patients

\begin{tabular}{|l|c|c|c|c|c|c|c|c|c|c|c|c|}
\hline \multicolumn{2}{|c}{ Etiology } & \multicolumn{3}{|c|}{ Sex } & \multicolumn{7}{c|}{ Age } \\
\cline { 3 - 14 } & Male & Female & Total & $0-10$ & $11-20$ & $21-30$ & $31-40$ & $41-50$ & $51-60$ & $61-75$ & Total \\
\hline MVC & Count & 126 & 19 & 145 & 11 & 37 & 53 & 16 & 15 & 6 & 7 & 145 \\
\hline & Percentage & $66.7 \%$ & $55.9 \%$ & $65 \%$ & $45.8 \%$ & $68.5 \%$ & $63.9 \%$ & $57.1 \%$ & $78.9 \%$ & $75 \%$ & $100 \%$ & $65 \%$ \\
\hline Fall & Count & 29 & 14 & 43 & 13 & 10 & 9 & 6 & 4 & 1 & 0 & 43 \\
\hline & Percentage & $15.3 \%$ & $41.2 \%$ & $19.3 \%$ & $54.2 \%$ & $18.5 \%$ & $10.8 \%$ & $21.4 \%$ & $21.1 \%$ & $12.5 \%$ & $0 \%$ & $19.3 \%$ \\
\hline Fight & Count & 21 & 0 & 21 & 0 & 3 & 12 & 5 & 0 & 1 & 0 & 21 \\
\hline & Percentage & $11.1 \%$ & $0 \%$ & $9.4 \%$ & $0 \%$ & $5.6 \%$ & $14.5 \%$ & $17.9 \%$ & $0 \%$ & $12.5 \%$ & $0 \%$ & $9.4 \%$ \\
\hline Sport & Count & 7 & 0 & 7 & 0 & 3 & 4 & 0 & 0 & 0 & 0 & 7 \\
\hline & Percentage & $3.7 \%$ & $0 \%$ & $3.1 \%$ & $0 \%$ & $5.6 \%$ & $4.8 \%$ & $0 \%$ & $0 \%$ & $0 \%$ & $0 \%$ & $3.1 \%$ \\
\hline Industrial & Count & 1 & 0 & 1 & 0 & 0 & 1 & 0 & 0 & 0 & 0 & 1 \\
\hline & Percentage & $0.5 \%$ & $0 \%$ & $0.4 \%$ & $0 \%$ & $0 \%$ & $1.2 \%$ & $0 \%$ & $0 \%$ & $0 \%$ & $0 \%$ & $0.4 \%$ \\
\hline Other & Count & 5 & 1 & 6 & 0 & 1 & 4 & 1 & 0 & 0 & 0 & 6 \\
\hline & Percentage & $2.6 \%$ & $2.9 \%$ & $2.7 \%$ & $.0 \%$ & $1.9 \%$ & $4.8 \%$ & $3.6 \%$ & $0 \%$ & $0 \%$ & $0 \%$ & $2.7 \%$ \\
\hline
\end{tabular}

The majority of patients were males [189 males (84.8\%), 34 females (15.2\%)], and the most affected patients were those with age of 21-30 years (37.2\%). According to etiology, motor vehicle crashes (MVC) was the most common cause $(65 \%)$, followed by falls (19.3\%) and violent assaults (9.4\%).

According to patients discharge status, the survival rate was $97.8 \%$, while mortality rate was $2.2 \%$ (Table 1).

\section{Distribution of patients based on anatomical sites of their facial fractures}

Data of the present study demonstrated that the most facial fractures were in the mandible (46.6), followed by fractures in zygoma and in mid-face.

Additionally, as shown in Figures 1 A\&B, the majority of mandibular fractures were at the ramus, followed by the angle and the body of the mandible, while the majority of fractures in mid-face were at Lefort II Figure 2A, followed by Lefort I and Lefort III Figure 2B.
TABLE (3) Distribution of facial fractures among the enrolled 223 patients according to anatomic site

\begin{tabular}{|l|c|c|c|}
\hline & Number & Percentage & Total \\
\hline Anatomical Site of the & & & \\
Fracture: & & & \\
Mandible & 104 & $46.6 \%$ & \\
Mid-face & 12 & $5.4 \%$ & $\mathrm{~F}=223$ \\
Zygoma & 24 & $10.7 \%$ & $\mathrm{P}=$ \\
Orbital bone & 5 & $2.2 \%$ & $100 \%$ \\
Mandible \& Zygoma & 17 & $7.6 \%$ & \\
Mandible \& Nasal & 4 & $1.8 \%$ & \\
Mid-face \& Nasal & 6 & $2.7 \%$ & \\
Mid-face \& Zygoma & 10 & $4.5 \%$ & \\
Zygoma \& Nasal & 2 & $.9 \%$ & \\
Zygoma \& Orbital & 11 & $5.3 \%$ & \\
Orbital \& Nasal & 3 & $1.3 \%$ & \\
Mandible \& Mid-face & 13 & $5.8 \%$ & \\
Mandible \& Mid- & & & \\
face\& Zygoma & 12 & $5.4 \%$ & \\
\hline Multiple facial & & & \\
fractures : & & & \\
Yes & 80 & $36.3 \%$ & $\mathrm{~F}=223$ \\
No & 143 & $63.7 \%$ & \\
\hline
\end{tabular}




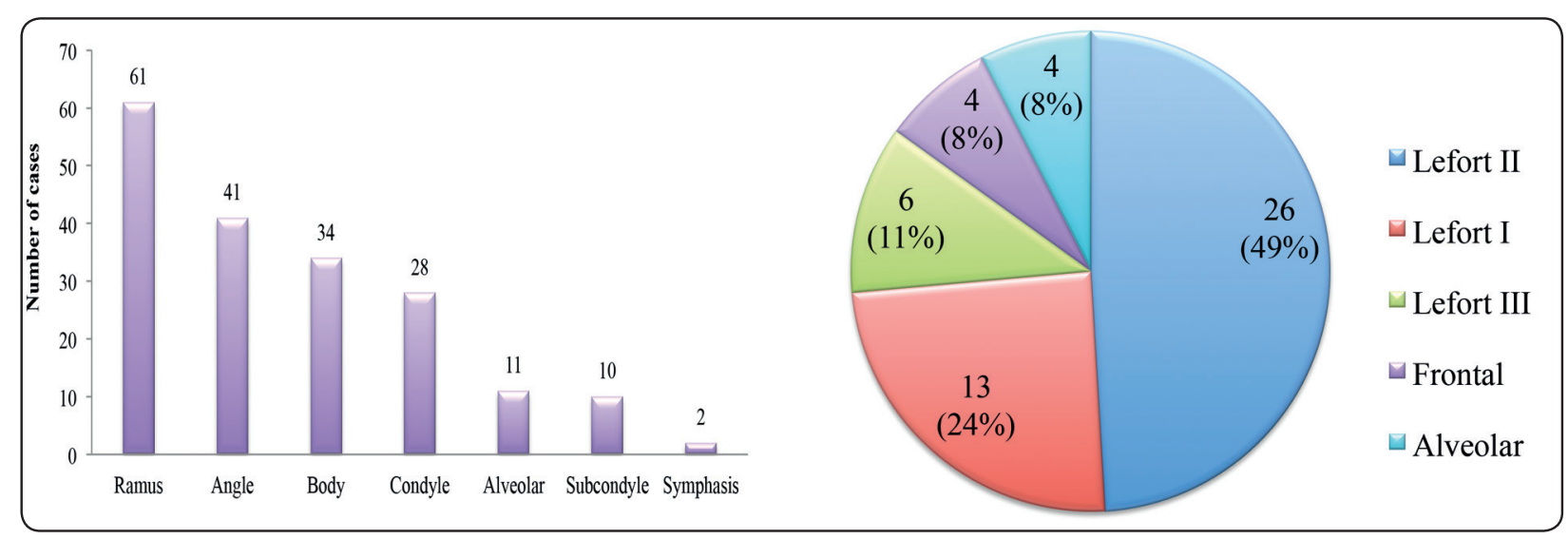

Fig. 1A- Mandibular Fractures

Figer 1B- Mid-Face Fractures

\section{Types and counts of different injuries}

During our searching on the types of different injuries among the analyzed 223 patients (Table 4), we found that a total of 201 of the 223 patients $(90.13 \%)$ had injuries. Among them, 54 patients (24.2\%) had head injury, and the most common factor for these head injuries was MVC (85.2\%). In addition, 125 of these 223 patients $(56.1 \%)$ had also other injuries, whereby extremities traumas were the most common type, followed by cut wounds and neurological traumas(Table 4).

TABLE (4) The types of different injuries among the analyzed 223 patients

\begin{tabular}{|c|c|c|c|}
\hline & Injury & $\begin{array}{l}\text { Number \& } \\
\text { percentage } \\
\text { of injuries }\end{array}$ & Total \\
\hline Heac & injury & $54(24.2 \%)$ & \\
\hline & Extremities & $37(16.6 \%)$ & \\
\hline & Cut wound & $33(14.8 \%)$ & \\
\hline & Neuro & $16(7.2 \%)$ & \\
\hline $\mathscr{\Xi}$ & Neuro \& Extremities & $12(5.4 \%)$ & \\
\hline$\Xi$ & Spinal & $7(3.1 \%)$ & $\mathrm{F}=223$ \\
\hline 䒕 & Extremities \& Thoracic & $6(2.7 \%)$ & $P=100 \%$ \\
\hline E & Thoracic & $5(2.2 \%)$ & \\
\hline$<$ & Neuro \& Thoracic & $3(1.3 \%)$ & \\
\hline & Others & $6(2.7 \%)$ & \\
\hline & Total & $125(56.1 \%)$ & \\
\hline Mult & le injuries & $22(9.9 \%)$ & \\
\hline
\end{tabular}

\section{Types of applied treatment}

As shown in Table 5, in regard to the applied treatment approach, 59.3\% of the patients were treated by internal open reduction and fixation (Int. ORF), and $22.0 \%$ were treated by closed reduction and fixation, while $12.1 \%$ were treated as conservative cases (12.1\%).

TABLE (5) Types of Treatment Among the Analyzed 223 Patients Applied

\begin{tabular}{|c|c|c|c|}
\hline $\begin{array}{c}\text { Type of } \\
\text { Treatment }\end{array}$ & Number & Percentage & \multirow{2}{*}{ Total } \\
\cline { 1 - 3 } Int. ORIF & 132 & $59.3 \%$ & \\
\cline { 1 - 3 } Ext. ORIF & 49 & $22.0 \%$ & \multirow{2}{*}{$\mathrm{F}=223$} \\
\cline { 1 - 3 } CRIF & 9 & $4.0 \%$ & \multirow{2}{*}{$100 \%$} \\
\cline { 1 - 3 } REC & 4 & $1.6 \%$ & \\
\cline { 1 - 2 } CON & 27 & $12.1 \%$ & \\
\cline { 1 - 2 } NON & 2 & $0.9 \%$ & \\
\hline
\end{tabular}




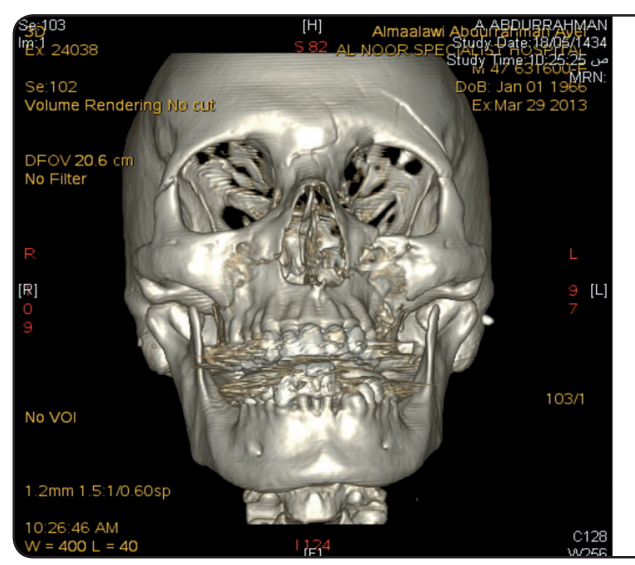

Fig. (2) A: Lefort II Fracture

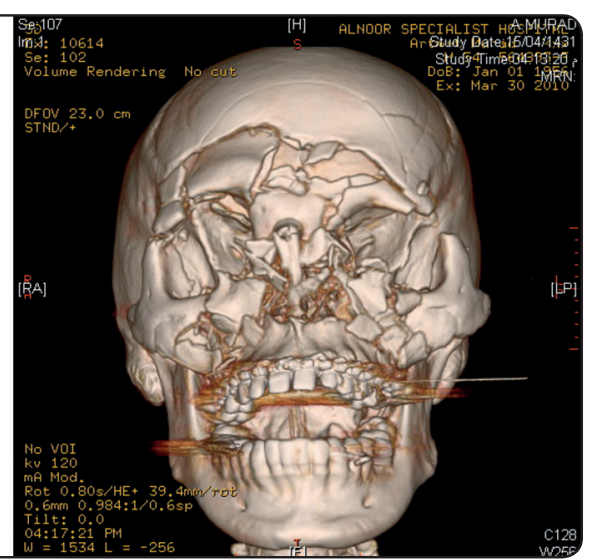

B: Lefort III Fracture

\section{DISCUSSION}

The purpose of this retrospective study was to highlight the common etiology and types of maxillofacial trauma (MFT) among patients in the Western region of Saudi Arabia. To achieve this objective, the charts of all MFT all patients referred to the Al-Noor Hospital, Holy Makkah from December 2010 to November 2012 were retrospectively reviewed. Pertinent data, including patient age, gender, and cause of injury, were obtained from 223 selected charts.

Data of the current study showed that motor vehicle crashes (MVC) were the major cause of patients diagnosed with MFT, and younger individuals were the most affected. These findings support the fact that MVC and road traffic accidents (RTAs) are responsible for many traumatic injuries in Saudi Arabia (Alahmed et al., 2004; Abdullah et al., 2013), particularly among young individuals (Almasri 2013; Abdullah et al., 2013). Also the incidence of MFT recorded in the present study is comparable to that in other studies, which have reported about 140 MFT cases per year, and the incidence of MVC is similar to those in other developing countries (Adeyemo et al., 2005; Almasri 2013; Barde et al., 2014).

In the present retrospective study, the highest percentage of MFT cases was reported among males; whereby male: female ratio was 5.6: 1 . This finding is in agreement with that reported recently in Riyadh City, Saudi Arabia by Abdullah et al. (2013); however, it is considered relatively high compared to ratios that have been previously reported in other regions in Saudi Arabia, such as 4:1 in Jeddah city (Shanks et al., 1994) and 4.8:1 in Almadina city (Rabi and Khateery, 2002), but it is low compared to ratios of 10:1 that have recently been reported in the Southern region of Saudi Arabia (Almasri (2013). These reported variations of MFT ratios among males and females in the different regions of Saudi Arabia might be attributed to the culture factors, whereby in our Western region as well as in the Southern region of Saudi Arabia females spend much of their time at home, males spend more time on motor vehicles as a primary means of transport and entertainment (Almasri, 2013).

NB: Int. ORIF = Intraoral Open Reduction and Fixation

$$
\begin{aligned}
& \text { Ext. ORIF }=\text { External Open Reduction and Fixation } \\
& \text { CRIF } \quad=\text { Closed Reduction and Fixation } \\
& \text { REC } \quad=\text { Reconstruction } \\
& \text { CON } \quad=\text { Conservative Treatment } \\
& \text { NON } \quad=\text { No treatment }
\end{aligned}
$$

Furthermore, the conservative nature of Saudi culture that the females are not allowed to drive may be a factor. However, a similar situation of high incidence of MFT among males than females have also been observed in various neighboring and non- 
neighboring countries such as United Arab Emirates (Gusztav and Adam, 2003; Bener and Crundall, 2005), Jordan (Bataineh, 1998), Tehran (Motamedi, 2003),Turkey (Ozkaya et al., 2009), Singapore (Tan and Lim, 1999), Brazil (Brasileiro and Passeri, 2006), Austria (Gassner et al., 2003), and Nigeria (Adeyemo et al., 2005).

Our finding that mandibular fractures were the most common type of maxillofacial fracture among our analyzed patients is comparable to the results of Abdullah et al. (2013) in Riyadh City, Saudi Arabia, as well as to the results of the retrospective studies of the etiologies and patterns of facial fractures in the United Arab Emirates (Klenk and Kovacs, 2003; Al Ahmed et al., 2004). This harmony may reflect the similar cultural habits of Saudi Arabia and the UAE (Abdullah et al. 2013). Moreover, despite differences in geographic locations and cultural properties, the present findings also support those of Maliska et al. (2009), who found that mandibular fractures accounted for the majority of maxillofacial fractures in Brazil.

In the present study, the percentage of fractures of the mild-face was secondary to the mandibular fractures. In contrast to our findings, a 10 year review in Austria has been conducted by Gassner et al. (2003) and showed that the most common facial injury site was the middle-third of the face. This difference might mainly be attributed to the reported etiologies of fracture in the studies, which were MVC in our present study and activities of daily life and falls in Gassner et al. study.

\section{CONCLUSIONS}

The results of the present 2-year retrospective study clearly indicate that MVC are a major health care threat and the major cause of MFT in the Western region of Saudi Arabia including Holy Makkah. Younger individuals, careless driving and speeding are major contributors to VMC rates. Males were more likely to be affected by MFT than females, perhaps due to the conservative nature of
Saudi society. Mandibular fractures were the most common maxillofacial fractures among the analyzed patients, although other facial and associated injuries are reported. These findings can be used to alert the community and authorities about this issue, leading to the development of community awareness and educational programs. We recommend the high demand for the application of stricter traffic rules and to ensure strict compliance of these traffic regulations to reduce the rate of MVC.

\section{Limitations of This Study}

Limitations of this study include, several cases were not recorded properly, so they were excluded from the study, and the assault between the husband and wife is difficult to be recorded in some cases as the family refuses to say truly.

\section{ACKNOWLEDGEMENT}

To professor Hassan Abdel-Dayem\& professor Hala Mokhtar Oral and Maxillofacial Surgery Faculty of Dentistry University of Alexandria, Alexandria City, Egypt. For their support by helping me to design this paper before starting and advices me how work is performed.

\section{REFERENCES}

1. Abdullah WA, Al-Mutairi K, Al-Ali Y, Al-Soghier A, AlShnwani A. Patterns and etiology of maxillofacial fractures in Riyadh City, Saudi Arabia. Saudi Dent J. 2013; 25(1):33-8.

2. Adeyemo WL, Ladeinde AL, Ogunlewe MO, James O. Trends and characteristics of oral and maxillofacial injuries in Nigeria: a review of the literature. Head Face Med. 2005;1:7-12.

3. Alahmed HE, Jaber M, Abu Fanas SH, Karas M. The pattern of maxillofacial fractures in Sharjah, United Arab Emirates: a review of 230 cases. Oral Surg. Oral Med. Oral Pathol. Oral Radiol. Endod. 2004;98(2):166-170.

4. Almasri M. Severity and causality of maxillofacial trauma in the Southern region of Saudi Arabia. Saudi Dent J. 2013;25(3):107-10. 
5. Auerbach SM, Laskin DM, Kiesler DJ, Wilson M, Rajab B, Campbell TA. Psychological factors associated with response to maxillofacial injury and its treatment. J Oral Maxillofac Surg. 2008;66(4):755-61.

6. Barde DH, Mudhol A, Ali FM, Madan RS, Kar S, Ustaad F. Efficacy of 3-Dimensional plates over Champys miniplates in mandibular anterior fractures. J Int Oral Health. 2014;6(1):20-6.

7. Bataineh AB. Etiology and incidence of maxillofacial fractures in the north of Jordan. Oral Surg. Oral Med. Oral Pathol. Oral Radiol. Endod. 1998;86(1):31-35.

8. Bener A, Crundall D. Road traffic accidents in the United Arab Emirates compared to Western countries. Adv. Transportation Stud. 2005;6:5-12.

9. Boffano P, Kommers SC, Karagozoglu KH, Forouzanfar T. Aetiology of maxillofacial fractures: a review of published studies during the last 30 years. Br J Oral Maxillofac Surg.2014;52(10):901-906.

10. Brasileiro BF, Passeri LA. Epidemiological analysis of maxillofacial fractures in Brazil: a 5-year prospective study. Oral Surg. Oral Med. Oral Pathol. Oral Radiol. Endod. 2006;102(1):28-34.

11. Chrcanovic BR. Factors influencing the incidence of maxillofacial fractures. Oral Maxillofac Surg. 2012;16(1):3-17.

12. Gassner R, Tuli T, Hächl O, Rudisch A, Ulmer H. Craniomaxillofacial trauma: a 10 year review of 9,543 cases with 21,067 injuries. J. Craniomaxillofac. Surg. 2003;31(1):51-61.

13. Gusztav Klenk, Adam Kovacs. Etiology and patterns of facial fractures in the United Arab Emirates. J. Craniofac. Surg. 2003;14(1):78-84.
14. Klenk G, Kovacs A. Etiology and patterns of facial fractures in the United Arab Emirates. J. Craniomaxillofac. Surg. 2003;14(1):78-84.

15. Lee K. Global trends in maxillofacial fractures. Craniomaxillofac Trauma Reconstr. 2012;5(4):213-22.

16. Mabrouk A, Helal H, Mohamed AR, Mahmoud N. Incidence, etiology, and patterns of maxillofacial fractures in Ain-Shams University, Cairo, Egypt: a 4-year retrospective study. Craniomaxillofac Trauma Reconstr. 2014;7(3): 224-32.

17. Maliska MCS, Lima Júnior SM, Gil JN. Analysis of 185 maxillofacial fractures in the state of Santa Catarina. Braz. Oral Res. 2009;23(3):268-274.

18. Motamedi MH. An assessment of maxillofacial fractures: a 5-year study of 237 patients. J. Oral Maxillofac. Surg. 2003;61(1):61-64.

19. Ozkaya O, Turgut G, Kayali MU, Uğurlu K, Kuran I, Baş L. A retrospective study on the epidemiology and treatment of maxillofacial fractures. Ulus Travma Acil Cerrahi Derg. 2009;15(3):262-266.

20. Rabi AG, Khateery SM. Maxillofacial trauma in al madina region of Saudi Arabia: a 5-year retrospective study. Asian J. Oral Maxillofac. Surg. 2002;14(1):10-14.

21. Shanks NJ, Ansari M, Al-Kalai D. Road traffic accidents in Saudi Arabia. Public Health. 1994;108(1):27-34.

22. Tan WK, Lim TC. Aetiology and distribution of mandibular fractures in the National University Hospital, Singapore. Ann. Acad. Med. Singapore. 1999;28(5):625-629.

23. Bicycle-related maxillofacial injuries: a double-center study 